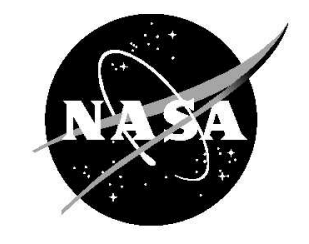

\title{
Simulation of Turbine Tone Noise Generation Using a Turbomachinery Aerodynamics Solver
}

Dale Van Zante and Edmane Envia

Glenn Research Center, Cleveland, Ohio 


\section{NASA STI Program . . . in Profile}

Since its founding, NASA has been dedicated to the advancement of aeronautics and space science. The NASA Scientific and Technical Information (STI) program plays a key part in helping NASA maintain this important role.

The NASA STI Program operates under the auspices of the Agency Chief Information Officer. It collects, organizes, provides for archiving, and disseminates NASA's STI. The NASA STI program provides access to the NASA Aeronautics and Space Database and its public interface, the NASA Technical Reports Server, thus providing one of the largest collections of aeronautical and space science STI in the world. Results are published in both non-NASA channels and by NASA in the NASA STI Report Series, which includes the following report types:

- TECHNICAL PUBLICATION. Reports of completed research or a major significant phase of research that present the results of NASA programs and include extensive data or theoretical analysis. Includes compilations of significant scientific and technical data and information deemed to be of continuing reference value. NASA counterpart of peer-reviewed formal professional papers but has less stringent limitations on manuscript length and extent of graphic presentations.

- TECHNICAL MEMORANDUM. Scientific and technical findings that are preliminary or of specialized interest, e.g., quick release reports, working papers, and bibliographies that contain minimal annotation. Does not contain extensive analysis.

- CONTRACTOR REPORT. Scientific and technical findings by NASA-sponsored contractors and grantees.
- CONFERENCE PUBLICATION. Collected papers from scientific and technical conferences, symposia, seminars, or other meetings sponsored or cosponsored by NASA.

- SPECIAL PUBLICATION. Scientific, technical, or historical information from NASA programs, projects, and missions, often concerned with subjects having substantial public interest.

- TECHNICAL TRANSLATION. Englishlanguage translations of foreign scientific and technical material pertinent to NASA's mission.

Specialized services also include creating custom thesauri, building customized databases, organizing and publishing research results.

For more information about the NASA STI program, see the following:

- Access the NASA STI program home page at http://www.sti.nasa.gov

- E-mail your question via the Internet to help@ sti.nasa.gov

- Fax your question to the NASA STI Help Desk at $443-757-5803$

- Telephone the NASA STI Help Desk at 443-757-5802

- Write to: NASA Center for AeroSpace Information (CASI) 7115 Standard Drive Hanover, MD 21076-1320 


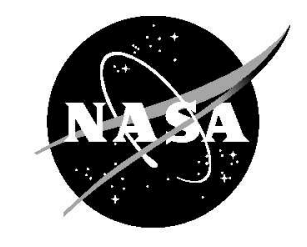

\section{Simulation of Turbine Tone Noise Generation Using a Turbomachinery Aerodynamics Solver}

Dale Van Zante and Edmane Envia

Glenn Research Center, Cleveland, Ohio

Prepared for the

15th Aeroacoustics Conference (30th Aeroacoustics Conference) cosponsored by AIAA and CEAS

Miami, Florida, May 11-13, 2009

National Aeronautics and

Space Administration

Glenn Research Center Cleveland, Ohio 44135 


\section{Acknowledgments}

This work was supported by the NASA Fundamental Aeronautics Program Subsonic Fixed Wing and Subsonic Rotary Wing

Projects. Computing and data visualization resources were supplied by the NASA Advanced Supercomputing site at

NASA Ames Research Center and the Advanced Computational Concepts Laboratory at NASA Glenn Research Center.

Trade names and trademarks are used in this report for identification only. Their usage does not constitute an official endorsement, either expressed or implied, by the National Aeronautics and Space Administration.

This work was sponsored by the Fundamental Aeronautics Program at the NASA Glenn Research Center.

Level of Review: This material has been technically reviewed by technical management.

Available from

NASA Center for Aerospace Information

7115 Standard Drive

Hanover, MD 21076-1320
National Technical Information Service 5301 Shawnee Road Alexandria, VA 22312

Available electronically at http://gltrs.grc.nasa.gov 


\title{
Simulation of Turbine Tone Noise Generation Using a Turbomachinery Aerodynamics Solver
}

\author{
Dale Van Zante and Edmane Envia \\ National Aeronautics and Space Administration \\ Glenn Research Center \\ Cleveland, Ohio 44135
}

\begin{abstract}
As turbofan engine bypass ratios continue to increase, the contribution of the turbine to the engine noise signature is receiving more attention. Understanding the relative importance of the various turbine noise generation mechanisms and the characteristics of the turbine acoustic transmission loss are essential ingredients in developing robust reduced-order models for predicting the turbine noise signature. A computationally based investigation has been undertaken to help guide the development of a turbine noise prediction capability that does not rely on empiricism. As proof-of-concept for this approach, two highly detailed numerical simulations of the unsteady flow field inside the first stage of a modern high-pressure turbine were carried out. The simulations were computed using TURBO, which is an unsteady ReynoldsAveraged Navier-Stokes code capable of multi-stage simulations. Spectral and modal analysis of the unsteady pressure data from the numerical simulation of the turbine stage show a circumferential modal distribution that is consistent with the Tyler-Sofrin rule. Within the high-pressure turbine, the interaction of velocity, pressure and temperature fluctuations with the downstream blade rows are all possible tone noise source mechanisms. We have taken the initial step in determining the source strength hierarchy by artificially reducing the level of temperature fluctuations in the turbine flowfield. This was accomplished by changing the vane cooling flow temperature in order to mitigate the vane thermal wake in the second of the two simulations. The results indicated that, despite a dramatic change in the vane cooling flow, the computed modal levels changed very little indicating that the contribution of temperature fluctuations to the overall pressure field is rather small compared with the viscous and potential field interaction mechanisms.
\end{abstract}

\section{Introduction}

The noise signature of a contemporary turbofan engine is comprised of an amalgam of different noise sources, the turbine component being just one of those sources. The turbine noise is always discernible in the overall engine noise signature and its relative importance has been on the rise with the advent of the ultra high bypass ratio engines. Several turbine noise prediction models were developed in the 1960s and 1970 s, but these are all empirically based and rely exclusively on steady state turbine operating parameters as their input. Consequently, these models are highly "tuned" to the engine data on which they are based and are not very robust at predicting the noise from significantly different turbine designs.

Mathews, et al. (Ref. 1) have presented an overview of these models and have defined the requirements for more physics-based turbine advanced prediction methods.

Noise from turbines became of interest at the end of the 1960s and design rules were developed to mitigate the turbine noise problem of 1970s and 1980s vintage engines. As bypass ratios increased in 1990 s vintage engine designs, and improved fan and jet noise reduction strategies were developed, the fan and jet noise contributions started to become less dominant. At the same time, shifting turbine design paradigms started a push toward lower blade counts and higher loading per stage. These design trends have increased the relative significance of turbine noise making it a more important part of the total engine noise signature. In the meantime, turbine noise prediction methods have not improved significantly and thus the current predicament where turbines are getting noisier in both their relative 
contribution and absolute level, but yet there are no reliable tools to predict turbine noise early in the design process (Ref. 2). With the introduction of ultra high bypass ratio engines, the accurate prediction of turbine noise has become even more important (Ref. 3).

To improve upon, and even move beyond empirical models, the turbine noise generation and propagation processes must be better characterized. Acquiring the necessary detailed flowfield measurements to do this is quite difficult due to the harsh environment that turbines operate in. One possible alternative to direct measurements is the use of highly detailed numerical simulations that may provide the necessary information for the development of new physics-based reduced order turbine noise prediction models.

Under the auspices of the Fundamental Aeronautics Subsonic Fixed Wing Project, NASA is currently funding core noise research focused on the generation and propagation mechanisms of combustor and turbine noise in the combustor-turbine-nozzle system as shown in Figure 1. This research effort is comprised of four elements. The first is a combustor noise Large Eddy Simulation work that is funded by NASA and carried out at Stanford University (Ref. 4) to characterize the temporal and spatial nonuniformities at the combustor exit plane (i.e., Station 4). The second element of this core noise research effort will use the results from the combustor simulations as an inlet boundary condition for a highpressure turbine (HPT) research investigation focused on the influence of combustor-turbine coupling on core noise generation. In the third element, which is the subject of this paper, simulations of the HPT with time-steady, circumferentially uniform inlet conditions have been underway in order to better characterize the tone noise generation mechanisms and their relative hierarchy. The fourth and final element of the core noise research effort will use the result of the HPT simulation work to serve as the inlet conditions for a low-pressure turbine (LPT) noise simulation study. This so-called inlet condition will naturally include any residual acoustic, vortical or entropic non-uniformity from the HPT that may persist through the last stage of the HPT. A detailed simulation of the LPT will be used to determine tone generation and propagation through the LPT and out the core nozzle exit plane. Ultimately, these four elements working in concert should provide a realistic end-to-end analysis of the combustor-turbine-nozzle subsystem and aid in the development of physics based models for turbine noise.

The initial step in the third element of this research effort is a proof-of-concept demonstration of the utility of the TURBO (Ref. 5) code to properly account for the essentials of the turbine tone noise generation physics. TURBO is an implicit, unsteady, multi-stage, Reynolds-averaged, Navier-Stokes, turbomachinery solver usually employed for detailed aerodynamic (i.e., performance) simulations of multi-stage turbomachinery. There are two objectives to this study. The first is to demonstrate that TURBO is a viable solver for this work and the second is to provide the LPT inflow plane boundary information.
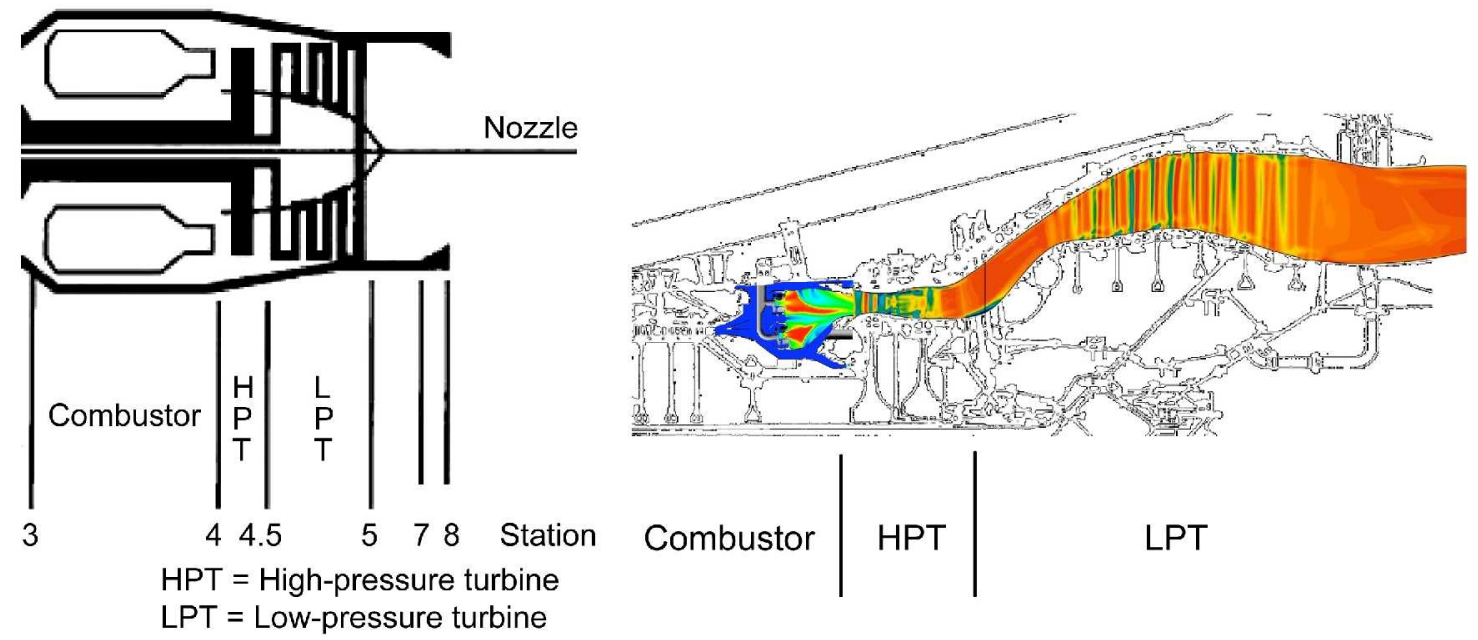

Figure 1.-Notional combustor-turbine section of a turbofan engine showing station numbering (left). The combustor and turbine flow path (right) from Reference 6. 
In what follows, the simulation setup is described followed by presentation of representative results from the simulated HPT turbine stage flowfields. Next the spectral/modal analysis of unsteady pressure extracted from the simulations.

\section{Nomenclature}

$\begin{array}{ll}m & \text { Circumferential mode } \\ \text { SPL } & \text { Sound Pressure Level, dB } \\ \text { W } & \text { Mainstream flow rate, non-dimensional } \\ \mathrm{X} & \text { Non-dimensional axial location } \\ \Omega & \text { Blade rotational speed, rpm } \\ 4 & \text { subscript, turbine inlet plane } \\ 41 & \text { subscript, rotor inlet plane } \\ 2 & \text { subscript, stage exit plane }\end{array}$

\section{Background and Simulation Setup}

The TURBO solver is $3 \mathrm{rd}$ order accurate in space, 2 nd order accurate in time, and uses double precision variables internally. The computational mesh was constructed such that the $2 \mathrm{xBPF}$ frequency content would propagate accurately within the domain. For a 2 nd order solver generally accepted practice requires 40 nodes per wavelength thus resulting in meshes that have 10 times the node count of typical aerodynamics meshes (Ref. 7).

The vane and blade airfoil counts were chosen so that $1 / 8$ th of the annulus is the geometrically periodic sector. The sector airfoil count is 5 vanes and 8 blades, which results in a 40-vane/64-blade stage which is representative of modern HPT designs. There are 200 nodes along each of the vane and blade chords with 100 nodes in the radial direction. The circumferential node counts are 208 per passage for the vane and 130 per passage for the blade. As a result, the sector domain as a whole contains 80 million nodes. A modified k- $\varepsilon$ turbulence model with wall functions was used (Ref. 8).

The tangential surfaces are periodicity boundary conditions as shown in Figure 2. The inlet and exit planes are locally 1-D non-reflecting boundary conditions. The mesh is stretched in the axial direction approaching the boundaries to damp oscillations and minimize the possibility of spurious reflections. The inlet boundary condition is comprised of a radial profile of total pressure and total temperature, but properties are taken to be uniform in the circumferential direction. A sliding mesh interface transmits information between the blade rows. Cooling flows on the blades, vanes, hub, and casing are included in the simulations as source terms at the blade/vane surface nodes.

To achieve stable and robust simulations, 300 iterations per blade passing period were used. This time step and mesh size yield maximum CFL numbers at the airfoil surfaces of $\sim 15$. The simulations were considered converged when the adiabatic efficiency did not vary outside of a band 0.15 points $(0.01=$ 1 percent $=1$ point) wide. A performance summary for the turbine stage is given in Table 1 . By running the simulation further, time histories of static pressure were extracted from the simulation at planes $1 / 2$ rotor chord distance upstream of the vane, at the upstream and downstream sides of the sliding interface, and downstream of the rotor. See Figure 2 . The flow field was sampled every 10 iterations which gives an effective sampling rate of $365.1 \mathrm{kHz}$. The blade passing frequency is $11.1 \mathrm{kHz}$. To achieve a sufficiently resolved FFT, 16 blade passings of time data were acquired to compute spectral content. Note that the geometric period would be 8 blade passings.

Two different simulations of the HPT stage were carried out, one with a nominal cooling flow for both vane and blade, and a second one in which the temperature of the vane cooling flow was radically altered in order to mitigate the vane thermal wake. For Case 1, the cooling flow temperatures were set to their nominal design values. In Case 2, the cooling flow temperatures of the vane were set to free stream 


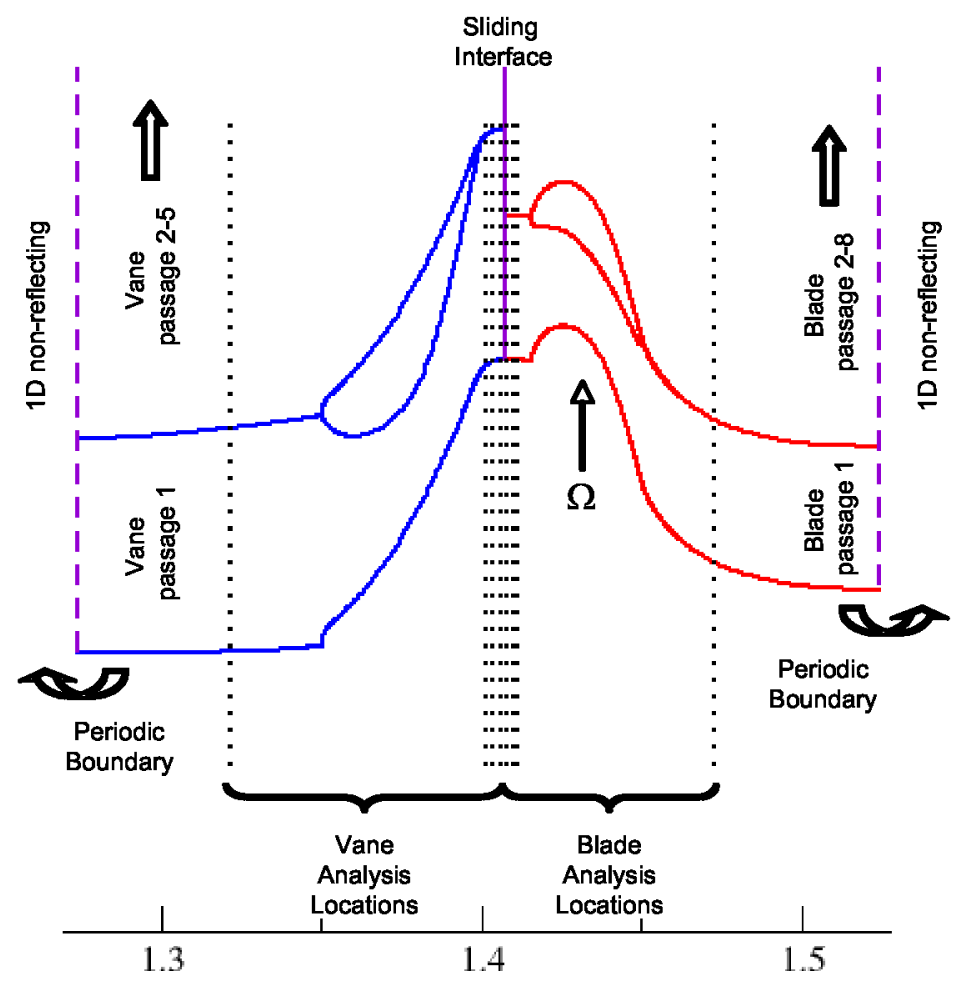

Figure 2.-The simulation domain showing boundary conditions and analysis plane locations.

TABLE 1.-TURBINE STAGE PERFORMANCE SUMMARY

\begin{tabular}{|l|c|c|}
\hline & $\begin{array}{c}\text { Case 1 } \\
\text { (cooled) }\end{array}$ & $\begin{array}{c}\text { Case 2 } \\
\text { (uncooled) }\end{array}$ \\
\hline Rotor inlet mass flow $\mathrm{W}_{41}$, normalized to Case 1 & 1.00 & 0.97 \\
\hline Pressure ratio, $\mathrm{P}_{\mathrm{T}, 4} / \mathrm{P}_{\mathrm{T}, 2}$ & 2.37 & 2.36 \\
\hline Temperature ratio, $\mathrm{T}_{\mathrm{T}, 4} / \mathrm{T}_{\mathrm{T}, 2}$ & 1.31 & 1.24 \\
\hline Nominal vane inlet abs. Mach no. & \multicolumn{2}{|c|}{0.1} \\
\hline Nominal vane exit abs. Mach no. & \multicolumn{2}{|c|}{0.9} \\
\hline
\end{tabular}

total temperature value at mid-span and mid-pitch. The mass flow rate of cooling flow was the same in both cases with only the cooling flow temperature having been changed. This was intended to greatly reduce the temperature deficit in the vane wake while leaving the velocity deficit relatively unchanged.

\section{Simulation Results}

The flow field inside the vane-blade gap contains sizable velocity, pressure and temperature fluctuations. All three of these can produce tone noise when interacting with blades and vanes. Figures 3 and 4 show an instantaneous view of the temperature fields for Cases 1 and 2 at mid span. Note the film of cold fluid that bathes the vane surface in Case 1 and then forms a cold wake, which is cut by the blades. Note also that the vane wake develops an instability for this case. For Case 2, the free stream to wake temperature difference is much reduced as a result of using the "hot" cooling flow. The influence of the blade potential field and the velocity gradients in the blade passage are evident in the distortion of the wake. 


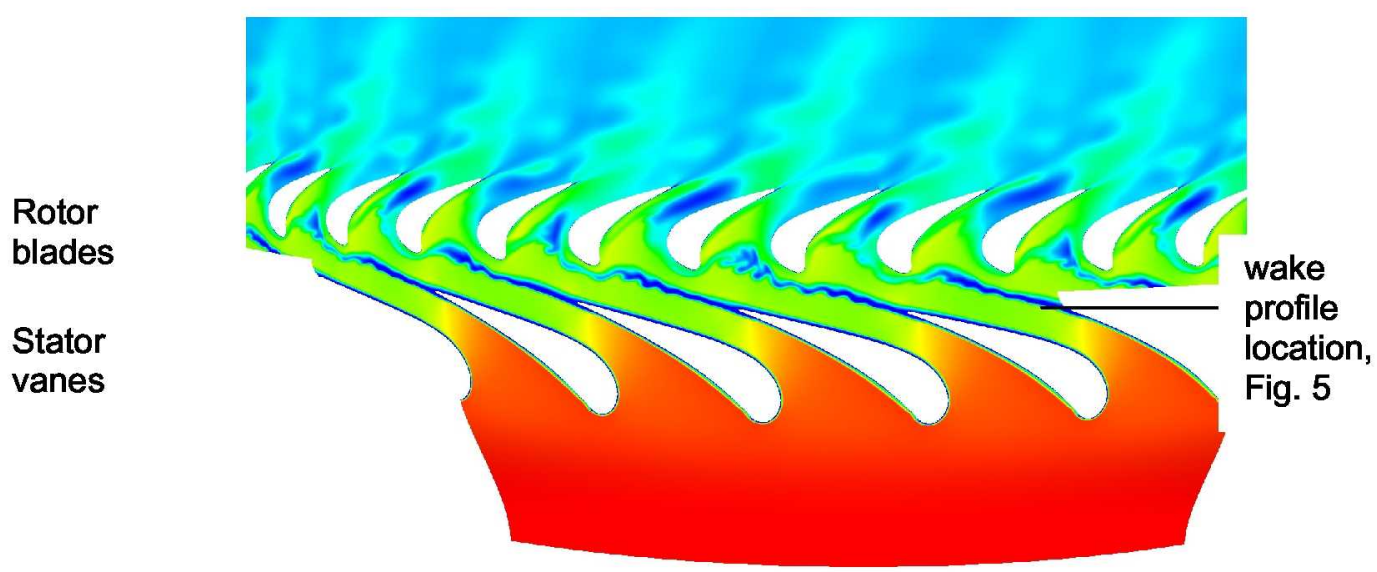

Figure 3.- Instantaneous view of static temperature on a 50 percent span surface for the cooled turbine, Case 1. The color scales are identical for both Figures 3 and 4 . Flow is from bottom to top. Rotor blade rotation is right to left.

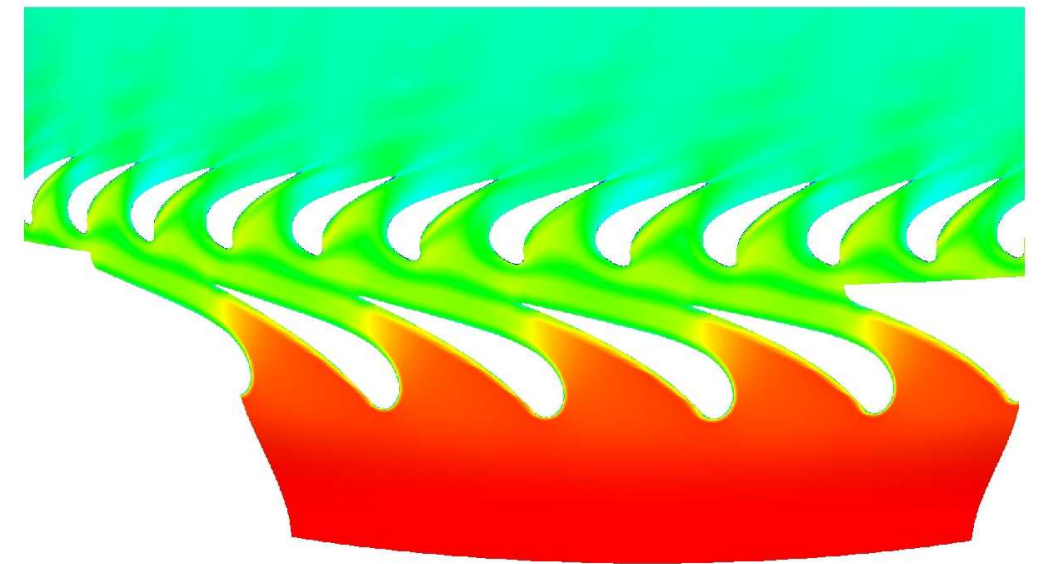

Figure 4.-Instantaneous view of static temperature on a 50 percent span surface for the "hot" cooling flow, Case 2.

Figure 5 shows an instantaneous view of the absolute velocity, static temperature and static pressure variation through the vane wake at 107 percent vane axial chord as shown in Figure 3. For reference, the vane-rotor gap is only 29 percent of vane axial chord at midspan. The wake-to-wake variation is primarily due to the potential field effect of the blades and secondarily to the instability that the Case 1 wake displays. Because these effects are so pronounced, a time average is not a suitable representation of wake width and depth. Thus, an instantaneous view is used and the wake interrogation plane is located close to the vane trailing edge where maximum non-uniformity could be expected. The velocity wake shown in Figure 5(a) has approximately 40 percent depth for Case 1 and somewhat less, approximately 30 percent, for Case 2. The change in the velocity wake is due to a coupling of the flow thermodynamic properties and a change in the cooling flow velocities because of the hot cooling fluid in Case 2.

The change in static temperature through the vane wake, i.e., the thermal wake, is shown in part (c) of Figure 5 . The thermal wake for the nominal case is approximately 33 percent deep, which means the wake minimum is several hundred degrees Rankine below the free stream temperature. For Case 2, the thermal wake has been "filled" to a depth of approximately 6 percent, which is an 80 percent reduction in the thermal wake depth. For completeness the static pressure variation are shown in part (b). The peak-topeak spatial variation of static pressure is approximately $4 \mathrm{~atm}$.

This is a combination of vane trailing edge base pressure, blade potential field and pressure variations due to the cooling flow injection at the vane trailing edge. 

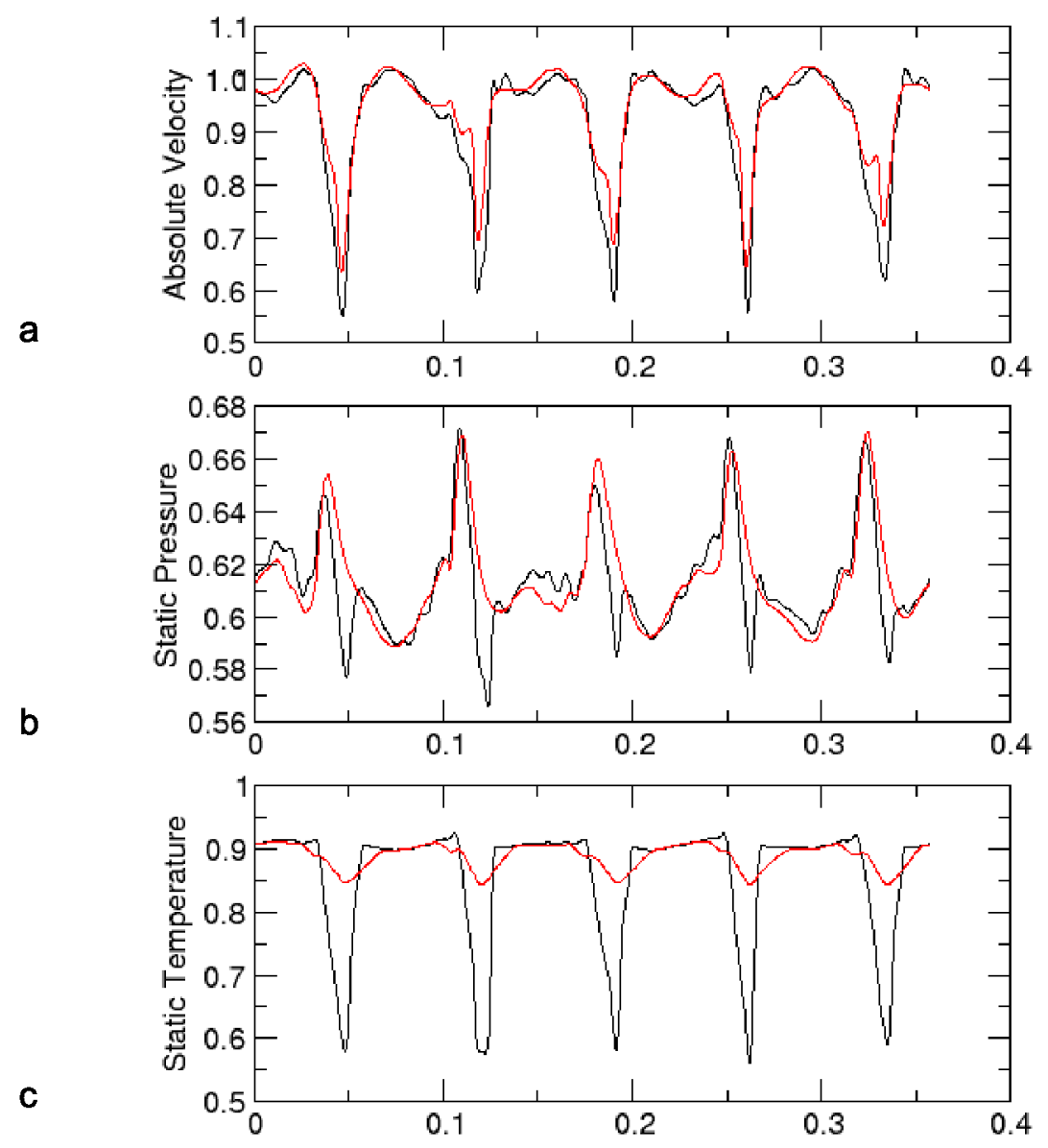

Figure 5.-Instantaneous view across the sector pitch of the vane wakes for Cases 1 and 2: (a) Absolute velocity, (b) Static pressure, and (c) Static temperature at mid-span, axial location $X=1.4024$. Black lines: cooled turbine, Case 1. Red lines: uncooled turbine, Case 2.

\section{Analysis of Unsteady Pressure Field}

Time resolved static pressure was extracted from the flowfields at planes throughout the solution domain as shown in Figure 2. Representative pressure traces are shown in Figure 6 for a position at midspan and mid-pitch located upstream of the vane at station $\mathrm{X}=1.3220$, and in the vane-blade gap at station $\mathrm{X}=1.4060$. Note the 45 -fold change in scale for the unsteady pressure amplitude upstream of the vane compared to the pressure amplitude in the vane-blade gap region. The pressure trace from the upstream location is also superimposed in red on the vane-blade gap trace for comparison. The fundamental period of the pressure signature is the blade-passing period. Figure 6(c) shows the ensemble average pressure trace for one rotor-passing period for comparison.

\section{Modal Analysis}

The time series data are reduced by spectral and modal analyses to determine the modes present at the various axial locations in the turbine. Figure 7 shows the modal results for the vane inlet axial location $\mathrm{X}=1.3220,50$ percent span, for the $1 \mathrm{x}, 2 \mathrm{x}$ and $3 \mathrm{xBPF}$ frequency tones for the cooled turbine (Case 1). Table 2 tabulates the most significant circumferential modes which are also the expected Tyler-Sofrin modes following the $n \mathrm{~B} \pm k \mathrm{~V}$ rule. The peak mode level for $1 \mathrm{xBPF}$ is $140.5 \mathrm{~dB}$ for $m=-16$. The second most significant mode at $1 \mathrm{xBPF}$ is $m=+24$ at $129.8 \mathrm{~dB}$. The other $1 \mathrm{xBPF}$ modes, not following the 
Tyler-Sofrin rule, are all $30 \mathrm{~dB}$ or more below the peak mode level. Therefore, all of the significant modes present are consistent with the Tyler-Sofrin selection rule. Furthermore, the rotor locked mode $(m=+64)$, which decays exponentially with axial distance from the rotor, is not present at the vane inlet. Then, arguably, in a region where the pressure variations should be acoustic in nature, the TURBO code appears to be resolving the acoustic aspects of the flow correctly on the fine grid used in this study. This assertion will need to be confirmed in detail with phase speed calculations at a future time.
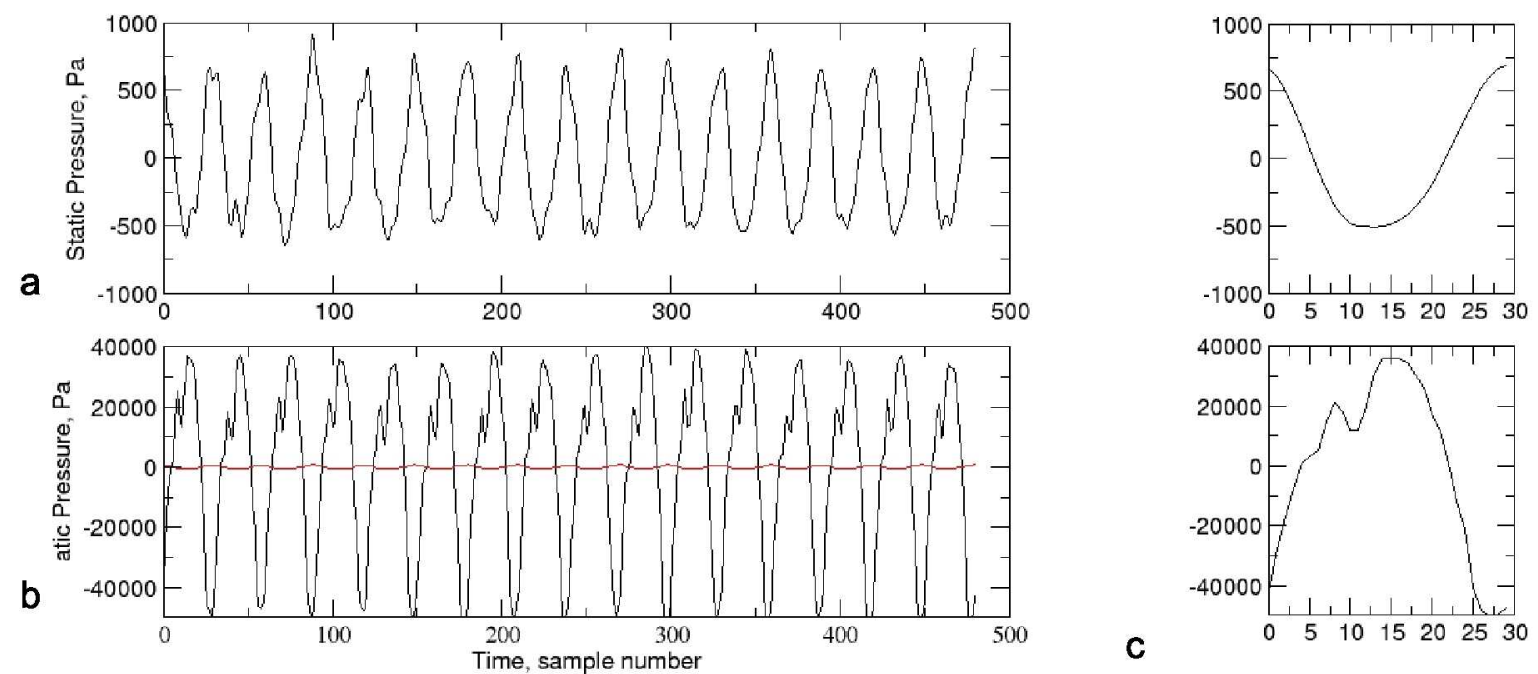

Figure 6.-Static pressure time traces at mid-span, mid-pitch (a) upstream of the vane $(X=1.3220)$ and $(b)$ in the vane-blade gap $(X=1.4060)$. The red trace in $(b)$ is the upstream pressure trace. Part (c) shows the ensemble average static pressure based on the rotor-passing period.

$$
\square \text { 1XBPF } \quad \text { 2XBPF }=3 \times 3 P F
$$

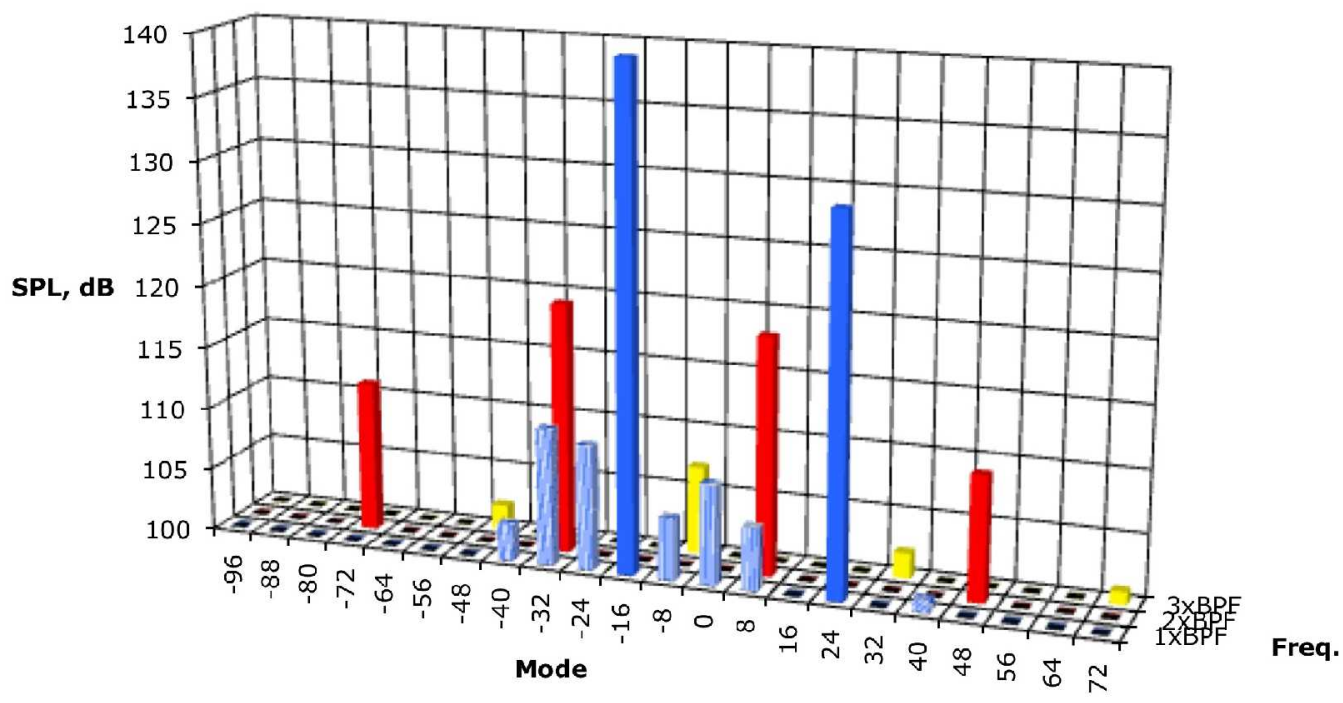

Figure 7.-Circumferential mode content at the vane inlet analysis plane, mid-span $(X=1.3220)$.

The light blue bars are modes that are not allowed by the Tyler-Sofrin rule.

TABLE 2.-MODES PRESENT AT THE VANE INLET ANALYSIS PLANE $X=1.3220,50$ PERCENT SPAN

\begin{tabular}{|c|c|c|}
\hline Frequency & Circumferential mode index $m$ from the simulation & Allowable Tyler-Sofrin mode index $m$ \\
\hline $1 \times B P F$ & $-16,+24$ & $\ldots,-96,-56,-16,+24,+64,+104,+144, \ldots$ \\
\hline $2 \times B P F$ & $-72,-32,+8,+48$ & $\ldots,-112,-72,-32,+8,+48,+88,+128, \ldots$ \\
\hline $3 \times B P F$ & $-48,-8,+32$ & $\ldots,-88,-48,-8,+32,+72,+112,+152,+192, \ldots$ \\
\hline
\end{tabular}




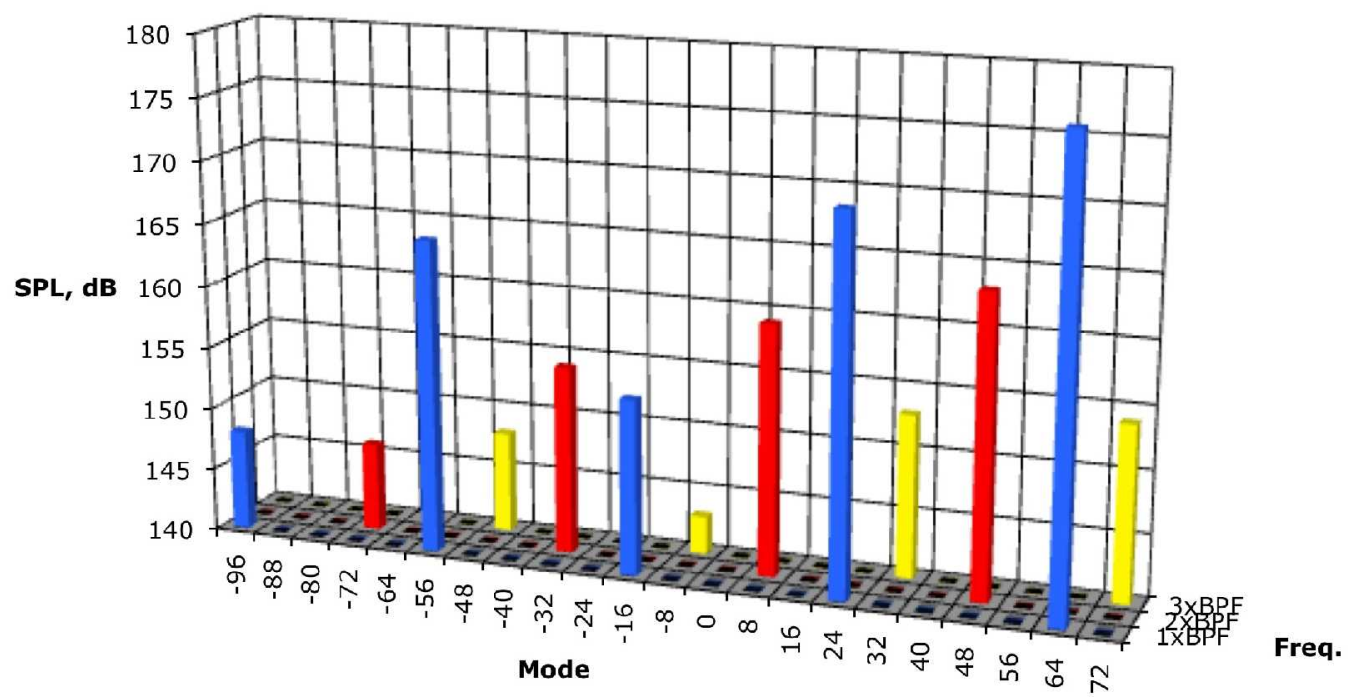

Figure 8.-Circumferential mode content in the vane-blade gap, mid-span $(X=1.4060)$.

Figure 8 shows the circumferential mode content in the vane-blade gap. There are many more modes present in the vane-blade gap and the pressure fluctuations cannot be considered acoustic a priori. In fact, since the analysis plane is now within the potential field of the rotor, the pressure fluctuations are likely a combination of both hydrodynamic and acoustic contributions. This is evident because the peak mode at $1 \times B P F$ is the rotor locked mode $(m=+64)$ at $176.9 \mathrm{~dB}$ is far higher than typical acoustic levels. The next most significant mode at $1 \mathrm{xBPF}$ is $m=+24$ at $170.5 \mathrm{~dB}$ which is also non-acoustic. All circumferential modes present are allowed by the Tyler-Sofrin relationship thus implying a vane-blade interaction mechanism is responsible.

In Figures 7 and 8 the circumferential mode content for a specific axial and radial location are shown. The radial variations of modes $m=+64,+24$, and -16 are plotted in Figure 9 for an axial location $X=1.4036$ in the vane-blade gap. The rotor locked mode $(m=+64)$ shows reduced amplitude with increasing radius because the blade leading edge is effectively swept back $3.5^{\circ}$ axially. That is, the blade leading edge is further from the constant axial location analysis plane at the tip than at the hub. The $m=+24$ mode has the characteristics of a propagating mode.

The mode $m=-16$ in Figure 9 shows an unusual behavior in the radial direction. As will be shown next, it also shows unusual behavior with axial distance from the blade leading edge. A satisfactory explanation for this anomalous behavior has proved elusive so far and will be pursued and addressed in a future paper. The behavior of these modes with axial distance at mid-span, including the impact of changes in the thermal wake depth, is shown next.

The description so far was focused on modal description of the pressure field. For the sake of comparison, in Figures 10 and 11, the circumferential mode content of the velocity field is shown. Figure 10 shows the velocity mode distribution upstream of the vane and Figure 11 the mode content in the vane-blade gap. The amplitude of the velocity fluctuation is expressed in $\mathrm{dB}$ using a reference velocity of $10^{-9} \mathrm{~m} / \mathrm{s}$. An examination of these two figures clearly shows that the dominant modes in the velocity field are also consistent with the Tyler-Sofrin selection rule and mirror those in the pressure field. Like the pressure field, the velocity field likely includes both hydrodynamic and acoustic contributions. 


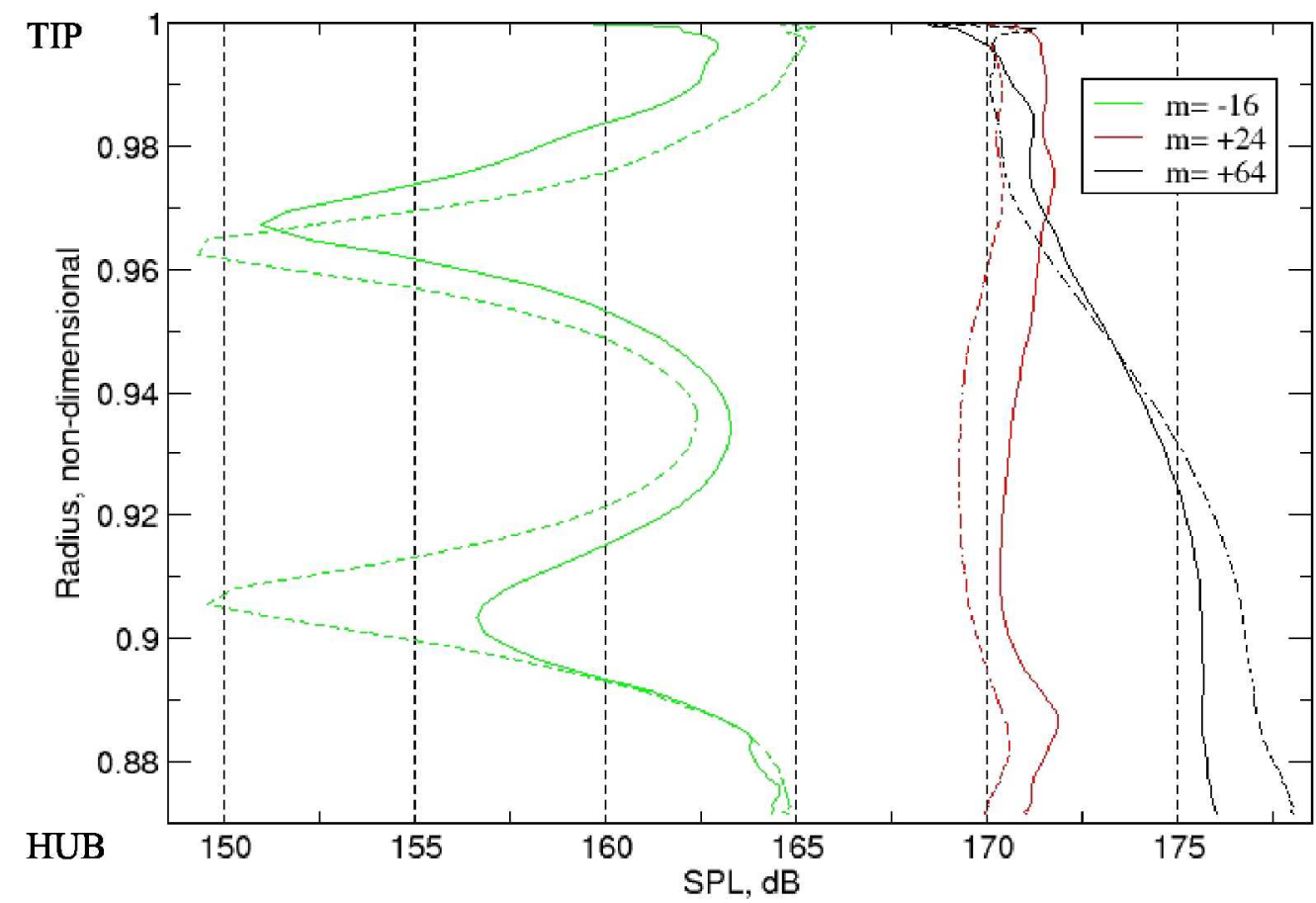

Figure 9.-Radial variation of $m=-16, m=+24$, and $m=+64$ at mid-span, axial station $X=$

1.4036. Solid lines are Case 1 (cooled turbine) and dashed lines are Case 2 (uncooled turbine).

1XBPF

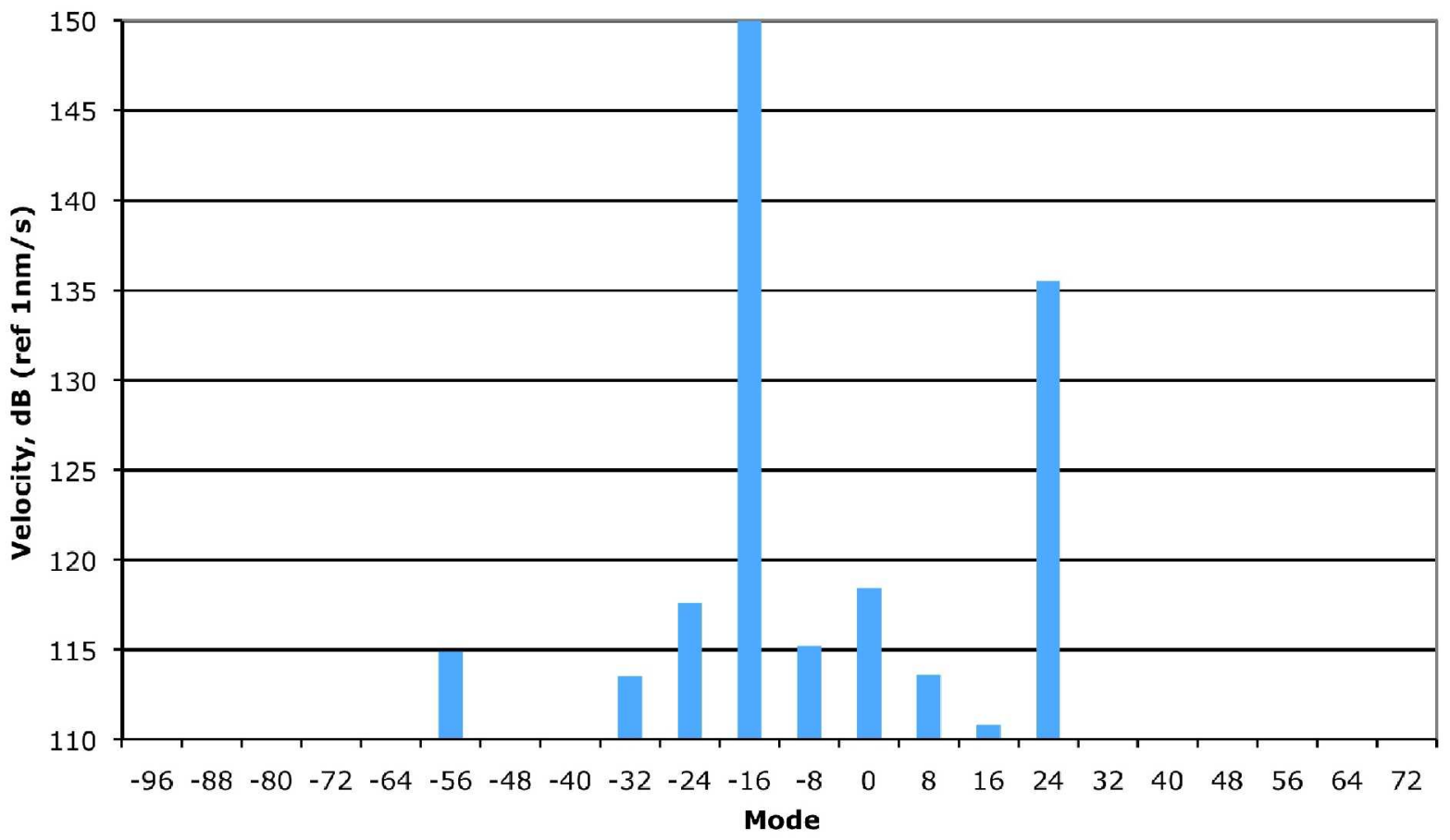

Figure 10.-Circumferential mode content of the velocity field at the vane inlet analysis plane, mid-span $(X=1.3220)$. 


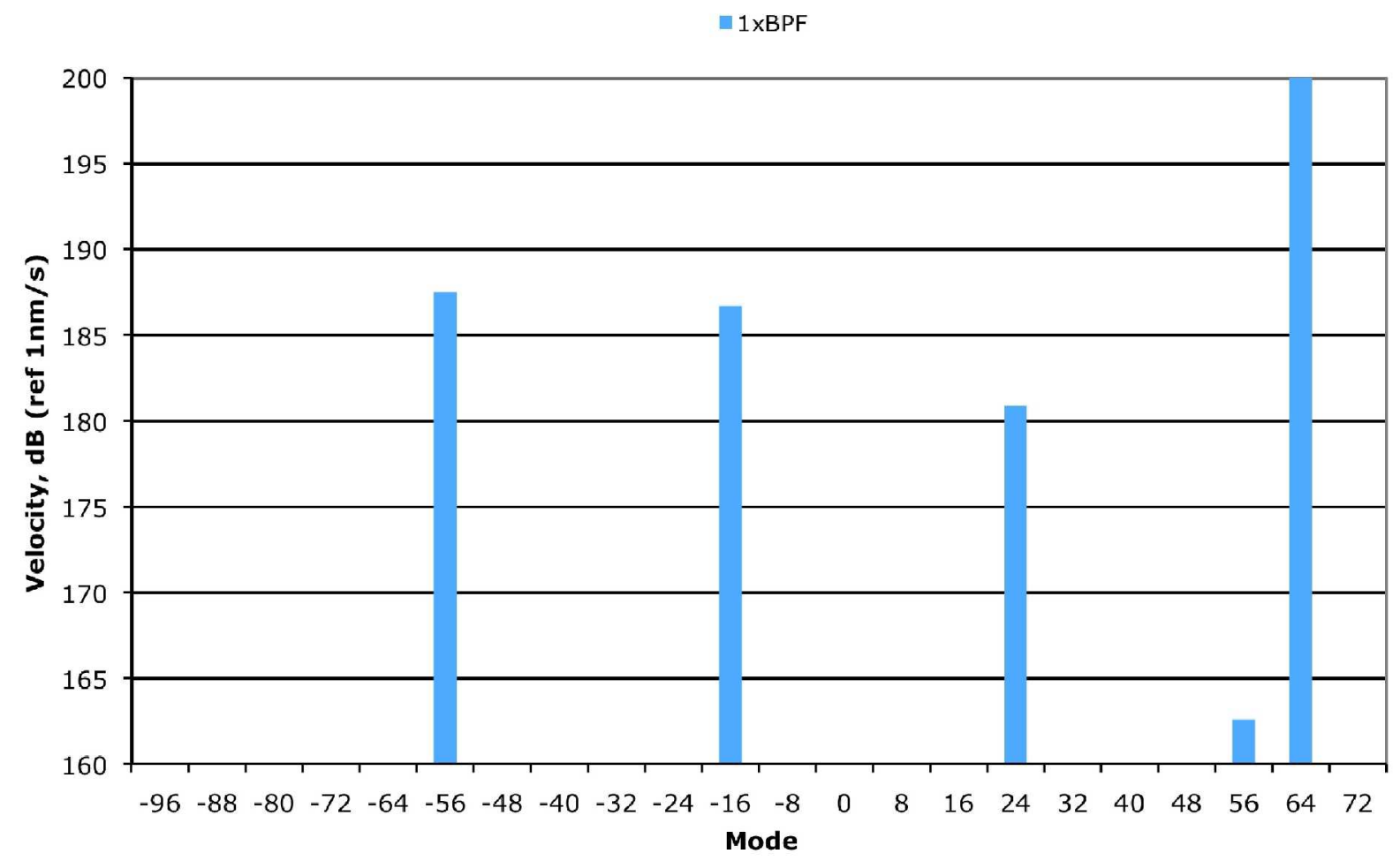

Figure 11. - Circumferential mode content of the velocity field vane-blade gap, mid-span $(X=1.4060)$.

TABLE 3.-CIRCUMFERENTIAL MODES AT MID-SPAN FOR 1XBPF IN THE VANE-BLADE GAP FOR CASES 1 AND 2

\begin{tabular}{|c|c|c|c|c|c|c|c|c|}
\hline & \multicolumn{4}{|c|}{ Case 1} & \multicolumn{4}{c|}{ Case 2 } \\
\hline $\mathrm{X}$ & $m=+64$ & $m=+24$ & $m=-16$ & $m=-56$ & $m=+64$ & $m=+24$ & $m=-16$ & $m=-56$ \\
\hline 1.4012 & 171.7 & 170.6 & 168.2 & 165.2 & 171.8 & 169.2 & 166.7 & 164.2 \\
\hline 1.4036 & 174.2 & 170.7 & 163.2 & 165.2 & 174.4 & 169.3 & 162.4 & 163.9 \\
\hline 1.4060 & 176.9 & 170.5 & 154.0 & 164.9 & 177.3 & 169.2 & 156.0 & 163.4 \\
\hline 1.4081 & 179.3 & 169.4 & 154.7 & 165.3 & 179.8 & 168.4 & 153.5 & 164.0 \\
\hline 1.4097 & 181.1 & 168.2 & 162.5 & 165.6 & 181.8 & 167.6 & 160.7 & 164.2 \\
\hline 1.4113 & 183.0 & 168.2 & 165.9 & 165.4 & 183.8 & 167.2 & 164.2 & 164.2 \\
\hline
\end{tabular}

\section{Thermal Wake Effects}

Table 3 compares the $1 \times B P F$ tone amplitudes in the vane-blade gap for Cases 1 and 2 . The axial variation of the modes within the vane-blade gap is shown in Figure 12 . The rotor locked mode $(m=+64)$ decays rapidly with axial distance from the blade leading edge as would be expected for the potential field of an airfoil. The mode $m=+24$ has characteristics reminiscent of a propagating acoustic mode. The mode $m=-16$ decreases then increases substantially in SPL with axial distance from the blade leading edge. This behavior, along with the unusual radial shape, is not yet fully understood.

For Case 2, where the thermal wake depth was reduced, SPLs for the modes shown are reduced uniformly by approximately $1.5 \mathrm{~dB}$. This level change is due in part to the reduction of the velocity wake depth. The results indicate that the thermal wake is not a significant factor in noise generation compared with the vortical and potential field mechanisms. In future work the source term capabilities of TURBO will be used to "fill in" the velocity deficit of the vane wake and separate the vortical and potential field influences on tone noise production. 


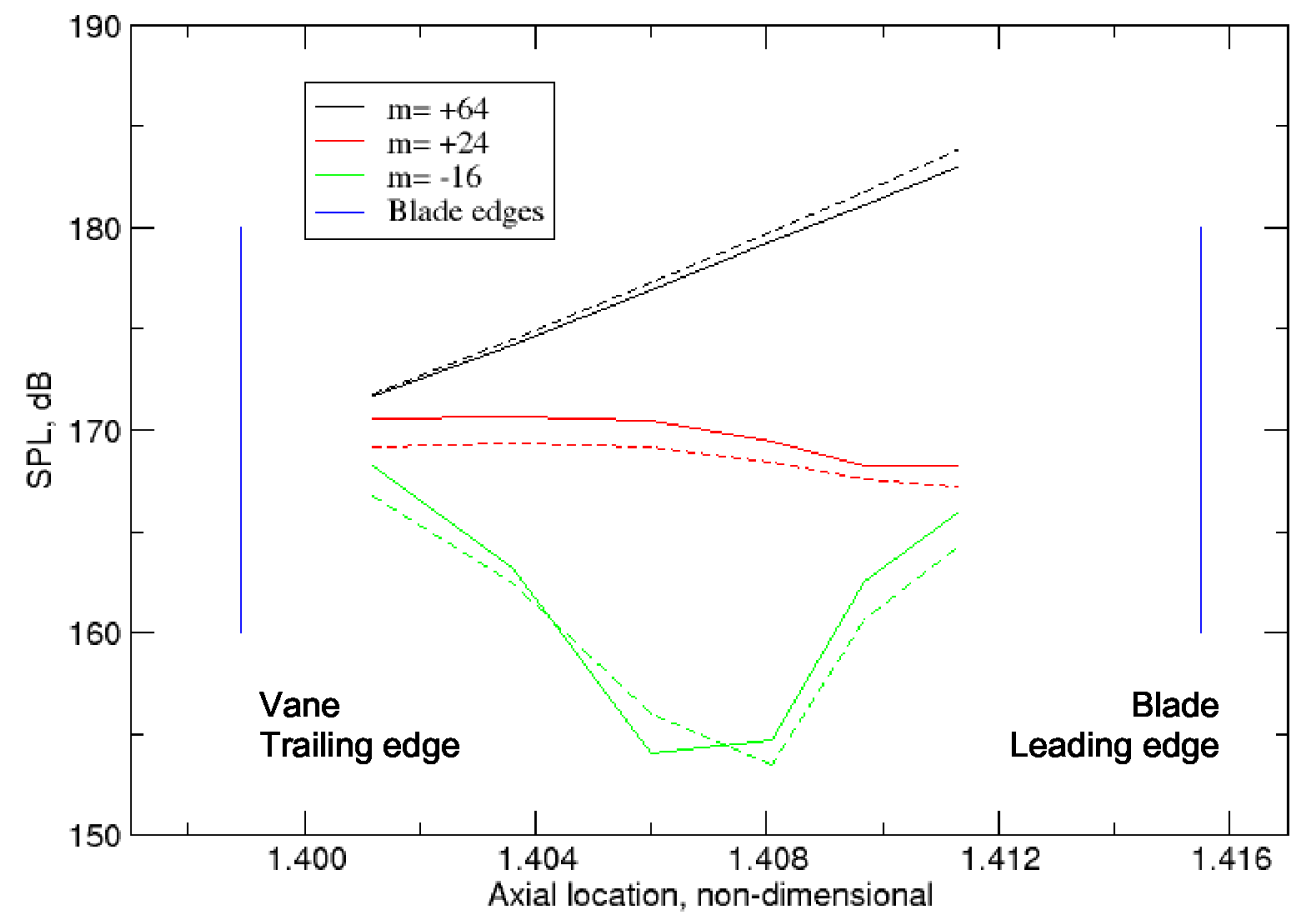

Figure 12.-Circumferential mode amplitude variation with axial location at mid-span in the vaneblade gap. Solid lines correspond to the results for Case 1 (cooled) and dashed lines correspond to Case 2 (uncooled). The blue lines indicate the axial locations of the vane trailing edge and blade leading edge.

\section{Summary}

TURBO code simulations of a high-pressure turbine stage have been used to demonstrate the utility of such a tool for determining turbine tone noise generation. Spectral and modal analyses of the timeresolved static pressure fluctuations from the simulations shows modes that are consistent with the TylerSofrin mode selection rule. While the modes show some familiar characteristics of acoustic modes, additional analysis is needed to establish their true character. The high-pressure turbine has three possible tone noise generation source mechanisms: velocity (or vorticity) wakes, temperature (or entropic) wakes, and potential field interacting with blades and vanes. It was shown in this paper that an 80 percent reduction in the temperature wake depth resulted in only $1.5 \mathrm{~dB}$ reduction of interaction mode SPLs. Given that part of the reduction is due to a decrease of the velocity wake depth, it is clear that, in the absence combustor outflow non-uniformity, entropic fluctuations, are not as effective a source of noise generation as are the vortical and potential field interaction mechanisms. Work is underway to separate the vortical and potential field influences on tone noise generation.

\section{References}

1. Mathews, D.C., Nagel, R.T., and Kester, J.D., "Review of Theory and Methods for Turbine Noise Prediction," AIAA Paper 1975-540, 1975.

2. Nesbitt, Eric, "Towards a quieter low pressure turbine: Design characteristics and prediction needs," submitted to the International Journal of Aeroacoustics, 2009.

3. Envia, E., "Progress Toward SFW N+1 Noise Goal," presentation made at the NASA Fundamental Aeronautics 2008 Annual Meeting, October 7-9, 2008, Atlanta, GA.

4. Giauque, A., and Pitsch, H., "Detailed modeling of combustion noise using a hydrodynamic/acoustic splitting model," Center for Turbulence Research, Annual Research Briefs, 2008, pp. 325-337. 
5. Chen, J.P., and Briley W.R., "A Parallel Flow Solver for Unsteady Multiple Bladerow Turbomachinery Simulations," ASME-2001-GT-0348. June 2001, New Orleans, LA.

6. Turner, M.G., Reed, J.A., Ryder, Robert and Veres, Joseph P., "Multi-Fidelity Simulation of a Turbofan Engine with Results Zoomed into Mini-Maps for a Zero-D Cycle Simulation," ASME Paper GT2004-53956, Proceedings of ASME Turbo Expo 2004, June 14-17, 2004, Vienna, Austria.

7. Hixon, R., Nallasamy, M., Sawyer, S., and Dyson, R., "Comparison of Numerical Schemes for a Realistic Computational Aeroacoustics Problem," International Journal of Aeroacoustics, Vol. 3, 2004, pp. 379-397.

8. Van Zante, D., Chen, J., Hathaway, M., and Chriss, Randall, "The Influence of Compressor Blade Row Interaction Modeling on Performance Estimates From Time-Accurate, Multi-Stage, NavierStokes Simulations," ASME Journal of Turbomachinery, Vol. 130, No. 1, pp. 011009-1 to 10. 


\begin{tabular}{|c|c|c|}
\hline \multicolumn{2}{|c|}{ REPORT DOCUMENTATION PAGE } & $\begin{array}{l}\text { Form Approved } \\
\text { OMB No. 0704-0188 }\end{array}$ \\
\hline \multicolumn{3}{|c|}{ 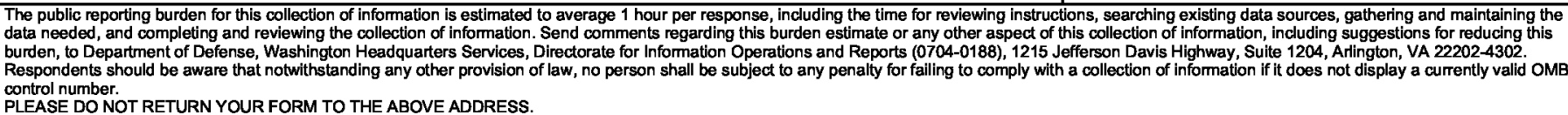 } \\
\hline $\begin{array}{l}\text { 1. REPORT DATE (DD-MM-YYY) } \\
01-03-2010\end{array}$ & $\begin{array}{l}\text { 2. REPORT TYPE } \\
\text { Technical Memorandum }\end{array}$ & 3. DATES COVERED (From - To) \\
\hline \multirow{3}{*}{\multicolumn{2}{|c|}{$\begin{array}{l}\text { 4. TITLE AND SUBTITLE } \\
\text { Simulation of Turbine Tone Noise Generation Using a Turbomachinery Aerodynamics Solver }\end{array}$}} & 5a. CONTRACT NUMBER \\
\hline & & 5b. GRANT NUMBER \\
\hline & & 5c. PROGRAM ELEMENT NUMBER \\
\hline \multirow{3}{*}{\multicolumn{2}{|c|}{$\begin{array}{l}\text { 6. AUTHOR(S) } \\
\text { Van Zante, Dale; Envia, Edmane }\end{array}$}} & 5d. PROJECT NUMBER \\
\hline & & 5e. TASK NUMBER \\
\hline & & $\begin{array}{l}\text { 5f. WORK UNIT NUMBER } \\
\text { WBS 561581.02.08.03.18.02 }\end{array}$ \\
\hline \multicolumn{2}{|c|}{$\begin{array}{l}\text { 7. PERFORMING ORGANIZATION NAME(S) AND ADDRESS(ES) } \\
\text { National Aeronautics and Space Administration } \\
\text { John H. Glenn Research Center at Lewis Field } \\
\text { Cleveland, Ohio 44135-3191 }\end{array}$} & $\begin{array}{l}\text { 8. PERFORMING ORGANIZATION } \\
\text { REPORT NUMBER } \\
\text { E-17217 }\end{array}$ \\
\hline \multirow{2}{*}{\multicolumn{2}{|c|}{$\begin{array}{l}\text { 9. SPONSORING/MONITORING AGENCY NAME(S) AND ADDRESS(ES) } \\
\text { National Aeronautics and Space Administration } \\
\text { Washington, DC 20546-0001 }\end{array}$}} & $\begin{array}{l}\text { 10. SPONSORING/MONITOR'S } \\
\text { ACRONYM(S) } \\
\text { NASA }\end{array}$ \\
\hline & & $\begin{array}{l}\text { 11. SPONSORING/MONITORING } \\
\text { REPORT NUMBER } \\
\text { NASA/TM-2010-216230 }\end{array}$ \\
\hline \multicolumn{3}{|c|}{$\begin{array}{l}\text { 12. DISTRIBUTION/AVAILABILITY STATEMENT } \\
\text { Unclassified-Unlimited } \\
\text { Subject Category: } 71 \\
\text { Available electronically at http://gltrs.grc.nasa.gov } \\
\text { This publication is available from the NASA Center for AeroSpace Information, 443-757-5802 }\end{array}$} \\
\hline
\end{tabular}

\section{SUPPLEMENTARY NOTES}

\section{ABSTRACT}

As turbofan engine bypass ratios continue to increase, the contribution of the turbine to the engine noise signature is receiving more attention. Understanding the relative importance of the various turbine noise generation mechanisms and the characteristics of the turbine acoustic transmission loss are essential ingredients in developing robust reduced-order models for predicting the turbine noise signature. A computationally based investigation has been undertaken to help guide the development of a turbine noise prediction capability that does not rely on empiricism. As proof-of-concept for this approach, two highly detailed numerical simulations of the unsteady flow field inside the first stage of a modern high-pressure turbine were carried out. The simulations were computed using TURBO, which is an unsteady Reynolds-Averaged Navier-Stokes code capable of multi-stage simulations. Spectral and modal analysis of the unsteady pressure data from the numerical simulation of the turbine stage show a circumferential modal distribution that is consistent with the Tyler-Sofrin rule. Within the high-pressure turbine, the interaction of velocity, pressure and temperature fluctuations with the downstream blade rows are all possible tone noise source mechanisms. We have taken the initial step in determining the source strength hierarchy by artificially reducing the level of temperature fluctuations in the turbine flowfield. This was accomplished by changing the vane cooling flow temperature in order to mitigate the vane thermal wake in the second of the two simulations. The results indicated that, despite a dramatic change in the vane cooling flow, the computed modal levels changed very little indicating that the contribution of temperature fluctuations to the overall pressure field is rather small compared with the viscous and potential field interaction mechanisms.

\section{SUBJECT TERMS}

Aircraft noise; Turbine; Aeroacoustics

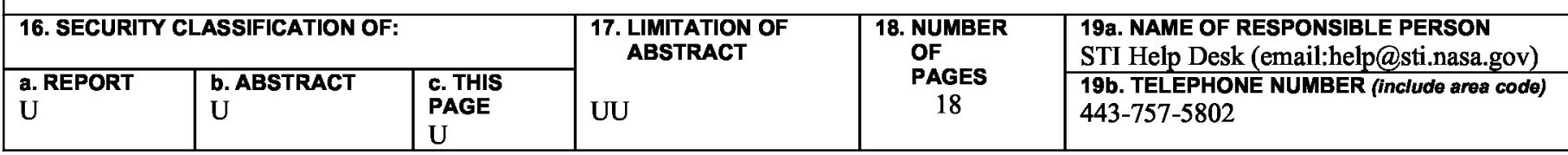



